\title{
"El toé te cura bonito": modos femeninos de dar salud en el pueblo awajún (Amazonía Peruana)
}

\author{
MARIA XIMENA Flores RoJas iD \\ Museu Nacional da Universidade Federal do Rio de Janeiro | Rio de Janeiro, RJ, Brasil \\ ximeflores.r@gmail.com
}

DOI 10.11606/issn.2316-9133.v30i2pe193520

resumen Este artículo presenta las primeras reflexiones sobre el uso de fitoterapia dentro de las familias Awajún de las regiones de San Martín y Amazonas. En especial, abordo las relaciones que despliegan las mujeres awajún con sus plantas de poder como el toé (Brugmansia suaveolens); una planta que es sembrada, cuidada, llamada y preparada por algunas madres awajún con el objetivo de dar vida y salud a sus hijos e hijas enfermas. La relación que cada mujer establece con sus plantas de toé es única. Similar a los procesos de formación de persona, las mujeres dueñas de las plantas tornan y reconocen la existencia de sus hijos vegetales por medio de cuidarlos, intercambio de substancia, dietas y resguardos. En reciprocidad, estos hijos vegetales se materializan como especialistas terapéuticos capaces de dar salud y vida a las familias awajún.

palabras clave Mujeres, awajún, plantas, toé, cuidado, enfermedad
"El toé te cura bonito": feminine ways of crafting health among the Awajún (Peruvian Amazon).

abstract This article presents the first reflections on the use of phytotherapy within the Awajún families of the San Martín and Amazonas regions. I address the relationships that Awajún women display with their power plants such as toé (Brugmansia suaveolens), a plant that is sown, cared for, called and prepared by some Awajún mothers with the aim of giving life and health to their sick sons and daughters. The relationship that each woman establishes with her toé plants is unique. Like the processes of person formation, the women owners of the plants return and recognize the existence of their vegetable children by taking care of them, exchanging substances, diets, and safeguards. In reciprocity, these vegetable children materialize as therapeutic specialists capable of giving health and life to the Awajún families.

keywords Women, awajún, plants, toé, care, illness 


\section{Introducción}

Los awajún ${ }^{1}$ son el segundo pueblo indígena amazónico más numeroso del Perú. Conocí por primera vez el territorio awajún de la región Amazonas en el 2014. ${ }^{2}$ Ese año permanecí en las comunidades de Kusu Kubaim, Kusu Pagata y Huampami; territorio al que retorné entre abril y junio de 2018. Mi objetivo era aproximarme a las nociones y experiencias de las familias awajún en torno al VIH/sida. Desde hace una década, los awajún del distrito de El Cenepa vienen enfrentando la llegada del VIH. Esta condición de origen apách (no-indígena) ha causado la muerte precoz de muchos de sus jóvenes.

Durante mi trabajo de campo, me quedó claro que las ideas biomédicas sobre el VIH (virus de inmunodeficiencia humana) y el sida (síndrome de inmunodeficiencia adquirida) no era algo central en el pensamiento awajún. Ellos tenían otros criterios para pensar los diversos malestares que los afligían. Las palabras biomédicas (VIH y sida) fueron insertas por los awajún dentro de sus concepciones de játa, una palabra que ellos traducen al castellano como "enfermedad", y de waweamu, una palabra que ellos traducen como "daño" o "brujería". De esta manera, los Awajún poseen nuevas nociones como "játa SIDA” o "enfermedad con síntoma de Sida" y "waweamu con síntoma de SIDA" o "brujería con síntoma de sida”, para referirse a sus propias experiencias de enfermedad y de daño asociadas al "VIH/sida" (Flores Rojas, 2019; Flores Rojas, 2020).

Mientras más escuchaba las historias de enfermedad que algunas familias compartieron generosamente conmigo, percibí la centralidad de las casas awajún como espacios de salud y el protagonismo de las madres de familia; quienes continuamente implementaban procesos de cuidado y de cura para hacer nuevamente fuerte el cuerpo de sus hijos e hijas enfermas. La existencia awajún que me presentaron mis interlocutores estaba en continuo peligro. Por ello, el cuerpo de los parientes enfermos era alimentado, tocado, sobado, hablado, pensado y sentido. Si bien los itinerarios terapéuticos fueron diversos, todos parecían coincidir en el papel central que asumían las madres awajún y sus plantas.

Cuando una persona awajún sentía algún malestar, aliviaba los síntomas con el uso de fármacos o plantas medicinales. Si los síntomas persistían y el paciente empeoraba, la persona enferma y su familia recurrían a especialistas más eficientes, como las plantas con espíritu de gente o plantas de poder como el toé (Brugmansia suaveolens), el tsúwak (variedad de toé) y la ayahuasca (Banisteriopsis caapi). La decisión sobre qué planta consumir dependía del acceso a cada planta y de los síntomas que se deseaban aliviar. Las madres de familia y distintos especialistas biomédicos y no-biomédicos acompañaban estos caminos terapéuticos.

\footnotetext{
${ }^{1}$ Este artículo fue posible gracias al profundo conocimiento que las familias y especialmente las mujeres Awajún de Amazonas y San Martín compartieron conmigo entre 2014 y 2020. Estoy especialmente agradecida a las conocedoras Rosa Bikayu y Herlinda Sejekam. Algunas partes de este artículo se presentaron en cursos y sesiones del PPGAS-MN-UFRJ. Los comentarios y lecciones de profesores y maestros como Luisa Elvira Belaunde, Aparecida Vilaça, Carlos Fausto y Marcio Goldman guiaron mis reflexiones.

${ }^{2}$ El pueblo awajún está desplegado en distintas regiones peruanas, tales como Loreto, Cajamarca, San Martín, Lima y, especialmente, Amazonas.
} 
Cuando leí la convocatoria del evento "Perspectivas Feministas na Amazônia Indígena” en marzo del 2021, recordé este protagonismo de las mujeres awajún y sus modos de dar salud mediante el uso de plantas de poder. En especial, recordé el uso del toé (Brugmansia suaveolens); una planta que era sembrada, cuidada y preparada por las madres para dar nuevamente vida a sus hijos e hijas enfermas. En estas páginas, presento las primeras reflexiones en torno a esta relación entre las madres awajún y sus plantas del toé.

El toé, llamado baikúa en lengua awajún ha sido documentada en otros pueblos jíbaro con los nombres de estramonio (Descola, 2005) y Datura sp (Brown, 1978; 1998). Su uso suele describirse principalmente en dimensiones chamánicas, principalmente masculinas. Por ello, el objetivo de este artículo es abordar esta otra dimensión y enfocarme en las relaciones de cuidado y de reciprocidad desplegadas cotidianamente por las mujeres awajún y sus plantas de toé.

Las mujeres awajún preparan sus cuerpos para tocar, sembrar, llamar y preparar sus plantas de toé. Estos procesos de cuidado cotidiano que siguen las mujeres con sus plantas permiten acceder a sus hijos e hijas enfermos a dimensiones sensibles donde se presentan los "doctores y doctoras del toé", especialistas terapéuticos que tienen la capacidad de diagnosticar y tratar enfermedades y/o casos de brujería. La relación de las mujeres con sus plantas del toé, permite que el espíritu de la planta se emparente y de salud a la familia. Similar a los procesos de formación de persona, las mujeres awajún tornan y reconocen la existencia de sus hijos vegetales por medio de cuidados, intercambio de substancia, dietas y resguardos. En reciprocidad, los hijos vegetales dan salud y vida a las personas que su madre les indique. La relación entre las mujeres awajún y sus plantas de toé nos presenta otros modos de pensar los procesos de salud y de enfermedad. Frente a la llegada de una enfermedad, antes de la búsqueda de especialistas rituales o chamánicos, los contextos cotidianos y domésticos, liderados por las mujeres, al entrelazar relaciones de cuidado más que humanos con las plantas y otros seres dan vida y salud al pueblo awajún.

Este artículo es una reflexión preliminar en torno a las acciones de mujeres, madres de familia mayores de cincuenta años residentes de comunidades awajún en las regiones de San Martín y Amazonas. Los nombres de las mujeres y de las comunidades han sido cambiados para resguardar la identidad de mis interlocutoras. Si bien existen varones awajún especializados en el cuidado y tratamiento con toé, espero con estas páginas presentar la potencia creadora y profundo conocimiento de las mujeres awajún con relación a sus plantas.

\section{Relaciones entre plantas y personas}

Las relaciones entre humanos y no-humanos es un tema recurrente en la etnología amazónica. Mitos, canciones de poder, rituales y las acciones en la vida cotidiana de los amerindios parecen desplegarse dentro de una multiplicidad de relaciones con ciertos animales y plantas, a quienes se les reconoce una condición de humanidad. Pues al contar con un "espíritu", como lo describe Descola (2008) en el caso Achuar, son poseedores de una conciencia reflexiva, capacidad comunicativa e intencionalidad que les permite ocupar una posición en relación con otros humanos (Ibidem: 25). 
Las posibles relaciones entre las personas amerindias y los "animales" se han abordado desde dimensiones de mestres-donos (Fausto, 2008), xerimbados (Erickson, 2012), depredación, reciprocidad y entrega de dones (Descola, 1998) o perspectivismo (Viveiros de Castro, 2016; Lima, 2005), por nombrar algunas aproximaciones. La relación entre las personas y sus plantas, por otro lado, es una dimensión que está siendo profundiza en diferentes estudios etnográficos.

Maizza (2017) en su etnografía con los Jarawara (Brasil) presenta la compleja relación de parentesco entre los humanos y los espíritus de sus plantas. Para la autora, la relación entre las plantas y sus dueños están mediadas por la seducción. Este término viene de la noción jarawara de jofa que significa "puedes mantenerte cerca de mí", "tienes que cuidarme" o "yo te cuido". Este término usado en el matrimonio, paternidad y la siembra entrelaza sentimientos de afecto con el cultivo de las plantas. Los padres tienen la voluntad y el deseo de criar a una especie por ello, persuaden a ese ser para que se mantenga cerca a ellos. Como identifica Mentore (2012) en su estudio sobre el cultivo de yuca en el pueblo Waiwai, las plantas son seres que tienen puntos de vista, afectos, recuerdos y varias formas de agencia. El carácter de cada planta dependerá del cuidado recibido de los dueños de la chacra. En consecuencia, la existencia de una especie llega a ser en algunos casos etnográficos, la materialización del que hacer humano y vegetal. Rival (2004) en el caso huaorani, nos presenta por ejemplo esa relación interconectada entre el crecimiento y la maduración de las personas huaorani y los árboles de pijuayo y balsa.

Cualquier planta cultivada no nace simplemente, ella nace para alguien. Gabriela Morim de Lima (2016: 14) en esta cita nos introduce a la cotidianidad de las mujeres Krahô, quienes en sus actos de cultivo, resguardo y cosecha muestran que las relaciones entre personas y plantas denotan acciones de familiarización entre las mujeres como madres de las chacras. Morim de Lima (2016) y Shiratori (2019) en los casos Krahô y Jamamadi, respectivamente, invitan a conocer la perspectiva de las plantas, sus intencionalidades, pensamientos, sentidos y afectos que abarcan relaciones de creación, intercambio y predación. El dueño cuida sus cultivos, con ayuda de sus parientes, y las plantas retribuyen este cuidado con frutos de abundancia. La gente-planta se sabe pariente y por ello cuida en retribución a su familia. Sin embargo, existe una ambivalencia en la gente-planta que puede pasar "de la benevolencia a la venganza dependiendo de la atención y a los cuidados necesarios de quien lo plantó" (Shiratori, 2019: 171).

Esta intencionalidad y categoría de humanidad extendida está presente en la relación que establecen las personas awajún con sus plantas del toé. Sin embargo, la planta del toé desde la etnología amazónica, ha sido asociada principalmente al uso medicinal y chamánico de algunos pueblos indígenas amazónicos. Langdon (2014:170), en el caso Siona, presenta el consumo del beji yajé o "yajé de la datura" (Brugmansia suaveolens) preparado por los chamanes de Buena Vista (Putumayo, Colombia). La borrachera rápida y prolongada causada por el beji siona, hizo que solo los más experimentados curacas la consumieran. La visión provocada por la toma del toé estaba siempre acompañada de la "gente de la datura" o beji bain (Ibidem: 178). Shepard (2019) también aborda el uso terapéutico del toé en el caso matsigenka. La Brugmansia es considerada la más fuerte y tóxica de todas las plantas en su 
farmacopea. Este pueblo, de lengua arawak, llama al toé con la palabra kepigari que se traduce como algo tóxico o venenoso. La intoxicación por la planta es una forma necesaria de crecimiento, que permiten a las personas comunicarse con el alma de otros seres.

Si bien el abordaje del toé desde sus dimensiones chamánicas es una contribución importante a los estudios amerindios sobre las plantas de poder. Mi intención en este trabajo es descentrar un poco del contexto chamánico y de masculino. En el caso awajún, el toé ha sido principalmente descrito por Brown $(1984 ; 1978)$ en su relación al proceso de formación masculina y a la cura de afecciones mediante la intervención de especialistas chamánicos. A continuación, siguiendo los lineamientos teóricos esbozados en esta sección exploraré otras relaciones posibles existentes entre el toé y las mujeres awajún.

\section{Bikut y el origen del toé}

El origen del toé (Brugmansia suaveolens) para el pueblo awajún está asociado al héroe cultural Bikut, demiurgo masculino de cuyo cuerpo surgieron los tipos de toé que se utilizan actualmente. El Bikut, un hombre poderoso gracias al consumo continuo del toé, enseñó a las personas awajún el camino para vencer la vida corta y lograr una visión de futuro próspero y guerrero. Así lo comentaban el muun ${ }^{3}$ Nankay Ampam, sabio de la comunidad Huampami, y Ruben Daichap, profesor y conocedor de la comunidad Kusu Kubaim, quienes narraron el mito de Bikut en junio de 2018:

Según nuestro mito. Dice que en aquel tiempo [a un niño] su papá le daba toé. En su hamaquita tomaba toé. Más o menos con 5 años cuando ya sabía hablar, le comenzaron a dar toé. [El niño] creció solo tomando toé. Él creció solo con dietas. Cuando pasaba la mareación [causada por la planta], volvía a tomar toé. Este hombre ya era transformado. La planta le hizo eso ¡Él se llamaba Bikut!

Cuando ya era adulto, Bikut como era sabio por la planta daba consejos a nuestros papás. Él les decía:

'No se junten con las mujeres. Cuando una mujer camina nunca estés detrás, siempre adelante ¡Detrás es peligroso! Su olor es fuerte'.

'A temprana edad no tengan relaciones [sexuales] ¡Se revienta la cabeza!'

'Cuando vas al baño y luego vienes sin lavarte las manos, llevas una porción de gusano en la mano y con eso comes. Por eso, cuando vas a comer debes lavarte [las manos]'

El Bikut podía verlo todo. De tanto tomar toé se volvió como tunchi [chamán]. Tomaba toé, toé, toé. Estaba con su lanza, sentado en su chimpuig [asiento ceremonial] y desde lejos veía todo. A veces una señorita venía luego de haber hecho relaciones [sexuales de adulterio] con otro hombre y el Bikut olía y decía: "esa mujer viene haciendo sus cosas y

\footnotetext{
${ }^{3}$ El muun Nankay falleció en su comunidad el año 2020. El COVID-19 fue el responsable de esta pérdida invaluable.
} 
me hace oler. Voy a matarla". Cuando los miembros de una familia se peleaban, el Bikut veía como si [estas personas] tuvieran sangre en la boca. Si alguien mataba a una persona, el Bikut veía el corazón del culpable lleno de sangre. El Bikut veía todo. Tenía los ojos cerrados y podía ver kilómetros y kilómetros. Atravesaba el cuerpo de las personas. Podía ver sus acciones y peligros.

Por eso, cuando se amargaba quería matar a las personas. Sus familiares le golpeaban el pecho y le decían: “ino hagas eso!”. [Frente al peligro] su familia decidió amarrarlo. Así pasaba sus días amarrado y sentado. La planta transformó espiritualmente al Bikut. ¡Él era poderoso! Para él era fácil participar en la guerra, nadie lo podía vencer. Lo desamarraban para ir a la guerra.

Una vez un enemigo se preparó como él [tomando toé] y ese enemigo venció al Bikut. ¡Lo mató! Su familia lo enterró bajo la tierra y después de un tiempo fueron a visitar donde estaba enterrado. Ahí encontraron una planta. ¡Encontraron el Toé! (Nankay Ampam y Ruben Daichap, 2018)

Con este último acto de transformación, Bikut un hombre awajún que se tornó poderoso con el consumo continuo del toé dio a los awajún el camino para tornarse personas con visión o waimaku por la incorporación del espíritu del Ajutap ${ }^{4}$ (Descola, 2005; Brown, 1984; Guallart, 1990). En las últimas décadas, este proceso de búsqueda de visión en los y las jóvenes ha dejado de practicarse. La llegada de la educación, el contacto y la religión han establecido nuevos parámetros de vida larga y próspera; sin embargo, el protagonismo del toé aún se percibe en los procesos cotidianos de búsqueda de salud. El Bikut un ser transformado por el consumo continuo de la planta del toé se tornó, luego de su muerte, en el mismo toé que a partir de ese momento es sembrado y criado por varones y mujeres awajún.

Según la versión recogida por Brown (1978: 124-127) entre los awajún de Alto Mayo del cuerpo de Bikut surgieron tres tipos de toé: del fémur derecho creció el shiwang baikuá (especie asociada a los procesos de formación y búsqueda de visión guerrera), del fémur izquierdo creció el tahimat Bikut (especie asociada a la búsqueda de prosperidad, abundancia y buena salud), y de la columna vertebral creció muntúk tsuák (planta utilizada para tratar enfermedades). Esta clasificación no fue compartida por las familias awajún con las que conversé. Durante mi trabajo de campo en el distrito de El Cenepa, algunas mujeres y un especialista de plantas sugirieron que del cuerpo del Bikut brotaron: la planta baikua (asociada

\footnotetext{
4 El Ajutap es el espíritu duplo guerrero que se presenta en forma de un animal poderoso o de otras múltiples figuras. "El Ajútap se manifiesta de acuerdo con el carácter, la capacidad y el nivel espiritual de cada individuo. Así, estas múltiples manifestaciones del Ajútap toman nombre de 'fuerza del viento', 'fuerza de la anaconda', 'fuerza del ikanmach -bosque-" (Edinson Tajuput Anguash, 2010). El solicitante al tocar el Ajutap incorpora su poder y asegura su éxito en cualquier batalla. Luego de incorporar el Ajútap, el nuevo waimaku (persona con visión) exclama ¡nunca me van a matar! ¡nunca me van a traicionar! jasí seguiré luchando! (Muun Nankay, 2018; Huampami en Flores, 2020).
} 
a la búsqueda de visión guerrera y de prosperidad futura) y la planta tsúwak (planta usada para diagnosticar y tratar enfermedades, en especial aquellas que se sospecha fueron causadas por un brujo tunchi; especialista con la capacidad de alojar dardos de daño con enfermedad en el cuerpo de las personas awajún).

No encontré una sola versión del mito ni de las especies que brotaron del cuerpo inerte de Bikut. Lo central para mis interlocutores era puntualizar que solo las personas "dueñas" de las plantas eran las únicas capaces de decir definitivamente que capacidades tenían sus plantas del toé.

Hay diferentes tipos y cada uno sabe para qué es. Hay toé para soñar visión, para mirar nuestro futuro, para soñar nuestra vida y ser persona útil, para ser persona valiente. Eso es para los jóvenes. Hay otra planta que solamente es para personas con fracturas, huesos quebrados y el toé lo coloca. Hay otro toé para la mujer que no puede dar a luz. Y según dicen también hay toé para ser tunchi (brujos). (Jaime, Especialista awajún en plantas, 2018).

Hay toé que se toma y ayuda a dar a luz, hay otro que cura cuando una persona se ha fracturado alguna parte del cuerpo, otro te da visión y este es el tsúwak que cura el daño y enfermedades (Victoria, madre awajún, 2020).

\section{Mujeres awajún y las plantas del toé}

El conocimiento especializado de las mujeres awajún sobre las plantas y las chacras están asociados a la potencia creadora de Nugkui. ${ }^{5}$ Nugkui es un ser central en la cosmovisión awajún. Este espíritu femenino residente del subsuelo dio a los y las awajún todas las especies cultivables, enseñó a las mujeres a velar por el bienestar de sus hijos e hijas vegetales y transmitió la sabiduría para fabricar la cerámica (Nugkui y Bosque de las Nuwas, 2021). Antiguamente las personas awajún no poseían ninguna especie cultivable. Nugkui al encontrarse con una mujer awajún y decidir dejar una hija suya (también llamada Nugkui) bajo el cuidado de una familia awajún, hizo que este pueblo acceda a todas las especies cultivables de la chacra. Esta primera relación de Nugkui con las awajún se transmitió de abuelas a madres y de madres a hijas; en una cadena infinita que se materializa cuando se siembra y cuida cada especie. Todo lo que se conoce y se consume se asocia este conocimiento que dejó Nugkui.

Las mujeres awajún asociadas a la potencia creadora de Nugkui cuentan así con un saber especializado en torno al uso de las plantas y otros seres del bosque. Ellas comparten

\footnotetext{
${ }^{5}$ Existe una literatura significativa en torno al mito de Nugkui. Distintos autores han recolectado diferentes versiones en torno a la llegada de Nugkui y cómo es que ella se relacionó con la mujer jibaro que la encontró. Descola (2005) presenta la versión del mito de Nugkui del pueblo achuar y Taylor (2000) profundiza la relación de Nugkui con las mujeres achuar del Ecuador. Brown (1984) y Reagan, (2010) presentan versiones del mito desde la visión del pueblo awajún de las regiones San Martín y Amazonas. Por otra parte, el mito narrado desde las propias autorías indígenas se encuentra en Chumap, Aurelio y Manuel García (1979) y Giucam, Cesar y Elvin Ramos (2015).
} 
con Nugkui una tutela conjunta de las plantas y por ello, establecen procesos de cuidado e intercambio de substancias con sus hijas e hijos para asegurar su correcto crecimiento. Como identificó Brown (1984:134), la producción awajún tiene fines más profundos que la mera subsistencia. "Los awajún tienen un mundo natural animado y habitado por seres espirituales con los que los humanos se comunican a través de cantos, rituales y sueños". Estos seres planta con categoría de "gente" tienen espíritu y deben ser tratados respetuosamente.

El caso del cultivo de la yuca, por ejemplo, es uno de los más documentado en los pueblos jibaro. Las plantas de la yuca recién sembradas tienen ansias de sangre y pueden afectar a los hijos pequeños de la dueña de la chacra. Las mujeres awajún para prevenir esa relación predatoria: 1) nutren a sus plantas con agua y achiote (Bixa orellana), 2) practican actividades rituales con el uso de cantos mágicos (anent) y piedras mágicas (nantag) para estimular el crecimiento de sus plantas, y 3) siembran o preservan la existencia de otras hierbas que simbióticamente ayudan en el crecimiento de la yuca (Taylor 2000; Brown1984). La potencia creadora de las mujeres awajún hacen que ellas establezcan relaciones de alianza y de reciprocidad con el espíritu de múltiples especies tanto agrícolas como terapéuticas. La relación que cada mujer establece con sus plantas es única. Por ello, a continuación, deseo presentar la relación que mis interlocutoras awajún han establecido con el espíritu de sus plantas del toé; una planta de poder que es cultivada con el objetivo de dar salud y vida a los miembros de la familia.

Para las familias awajún con quienes conversé, el toé era un ser que "nunca mentía" y que "curaba todo". En especial las enfermedades awajún que se percibían como más fuertes y diferentes que las enfermedades no indígenas. Por ello, frente a la llegada de algún signo de amenaza - como una enfermedad repentina, la pérdida de movilidad, de apetito o de razón - las familias y, en especial, las mujeres activaban ese conocimiento heredado de sus madres, hermanas y abuelas.

La señora Tania, una mujer awajún de aproximadamente 60 años, recordaba cómo su abuela hace más de treinta años le heredó su planta de toé y le enseñó cómo tratarla. "Mi abuela decía, 'a cualquier enfermedad, a tu hijito le tienes que dar así'. Entonces yo traje la planta y la sembré". La transmisión intergeneracional de saberes y de poderes de cura era, en consecuencia, el resultado de prácticas de resguardos que fueron llevadas a cabo por su abuela y de la escucha de los consejos recibidos a su vez por su propia madre. Como veremos a continuación, esta red de relaciones y restricciones se hicieron necesarias para proteger el poder de la planta.

Para la señora Tania, el cuidado de la planta iniciaba con su siembra: "antes de que amanezca, no vas a comer, no haces relación (sexual), sin desayuno te vas. Sacas las hierbas y ahí lo siembras. Luego de sembrar, debes hacer un día se dieta. Se come plátano y yuca, nada caliente". Luego de ser sembrado, el toé demandaba un cuidado especial. Durante las visiones causadas por la ingesta del toé, la planta se comunicaba con sus dueñas para transmitirles distintos mensajes. Por ejemplo, les podía avisar que se sentía incómodo o maltratado por la forma en que lo habían cogido o, en otros casos, pedían ser vestidos. Ese fue el caso de una mujer, a quien su toé le pidió, que lo vista. "Cuando el toé tiene ya palitos, llevas ropa en pedacitos”. Otras mujeres comentaban que la ropa que amarraban en la planta 
era una especie de intercambio dado al espíritu de la planta por haberle cortado un tallo. Este deseo de vestir ropa revelaba la intencionalidad del toé y conciencia que tiene sobre sí mismo. Al ser consiente de esa relación de reciprocidad con sus dueñas, la planta solicitaba un mejor trato para poder dar a cambio su poder de cura a las familias. En consecuencia, el poder y la eficacia del toé dependían de la calidad de relaciones que las mujeres awajún establecían con sus plantas. Por eso las madres actuaban cuidadosamente para no ofender al espíritu de sus plantas.

Como sugiere Morim de Lima (2016) en el caso de las mujeres Krahô, las plantas cultivadas no brotan por si solas. Ellas brotan para alguien, en respuesta a las prácticas de cuidado y resguardo que dan sus dueñas en periodos de siembra, crianza y toma de la planta. La relación que se puede generar entre las plantas y las mujeres es, por tanto, una relación única y particular entre cada dueña y su planta. Las mujeres awajún preparan y limpian sus cuerpos para tocar, llamar y cuidar de su toé. La mujer, en consecuencia, es coproductora de sus cultivos. El cuerpo conocedor de las mujeres hace y se hace con relación a estas otras existencias. Si el cuerpo awajún se fabrica lenta y continuamente en un flujo constante de acciones que involucran alimentación, abstinencia, rituales y entrenamiento formal (Aparecida, 2005: 447), el toé al ser parte de estos actos se va emparentando con su madre awajún. Similar a los procesos de formación de persona (Seeger, Da Matta \& Viveiros de Castro, 1979), las mujeres awajún establecen procesos de cuidado e intercambio de substancias con sus hijas vegetales para asegurar el correcto crecimiento de sus cultivos.

\section{¡El toé te cura bonito!: los doctores de las plantas}

En las primeras conversaciones con las familias awajún del distrito de El Cenepa comencé a notar la continua referencia a un tiempo pasado donde no había enfermedades. "Antes jata atsú", era la frase que se repetía continuamente entre los abuelos y abuelas awajún; quienes recordaban que antes de la llegada de los no-indígenas se vivía con pocas afecciones que eran rápidamente aliviadas con el uso de sus plantas. En las últimas décadas esta realidad ha cambiado. La llegada de colonos, comerciantes, miembros de la iglesia y la formación de comunidades trajeron consigo la diseminación de enfermedades en los territorios indígenas. Condiciones como la anemia, gastritis, diabetes, epilepsia, tuberculosis, VIH, entre otras, se han vuelto parte de la cotidianidad awajún y por ello, mis interlocutores consideraban que su existencia estaba en continuo peligro.

Cuando un miembro de la familia caía enfermo, sus parientes activaban un sistema de cuidado diario donde, de acuerdo con la gravedad de la situación, el miembro enfermo era alimentado, tocado, sobado, pensado y sentido. La cocina y los ambientes anexos eran los espacios centrales de cuidado y las madres asumían el seguimiento detallado y diario de cada signo de alerta (Flores Rojas, 2019). Si luego de haber consumido fármacos y plantas, el pariente no mejoraba, la familia se planteaba buscar un especialista más efectivo: el toé.

El toé es un aliado central en la búsqueda de salud. Las madres awajún que han resguardado al toé a través de sus cuidados, piden a sus plantas que lleguen a atender a sus hijos e hijas enfermos. La planta del toé al ser un umbral de ingreso a un ámbito de visión alterno permite a la persona enferma y a su familia acceder a un diagnóstico y tratamiento 
gracias a la presencia del espíritu de la planta. En especial, las familias recurrían al tsúwak; una variedad de toé, que era asociado a fines terapéuticos por la capacidad de traer a los "doctorcitos". Seres como humanos que diagnosticaban, trataban y curaban a las personas enfermas.

El llamado del espíritu del toé implicaba dietas, resguardo sexual y un cuidado especial por parte de la madre y del paciente. Para extraerlo, la madre utilizaba un palo de madera afilado y comenzaba a raspar poco a poco la corteza de la planta, mientras le susurraba: "toé, tú tienes que ayudar a curar, no tengas miedo, jayúdale! Te pido tu fuerza para que cures" (Señora Norma, El Cenepa, 2018). Este llamado se hacía solo después de haber cumplido un resguardo de dietas y abstinencia sexual: "Cuando raspamos no comemos, no tenemos relación, no tomamos masato [bebida fermentada de yuca]. Después comemos chapo [bebida de plátano maduro] y una yuquita nada más". Luego de haber extraído correctamente la piel vegetal del toé, esta se "chancaba bien" para sacarle el jugo y se hacía hervir en una ichínak (olla de arcilla de boca alta). Cuando la bebida estaba lista era administrada al paciente. El cuerpo dietado de la madre y del paciente permitía que el espíritu del toé escuche su llamado. Los cuerpos que habían consumido alimentos grasosos y/o con olores perfumados eran rechazados por el espíritu de la planta, por ello se tomaba mucho cuidado en no ofenderla.
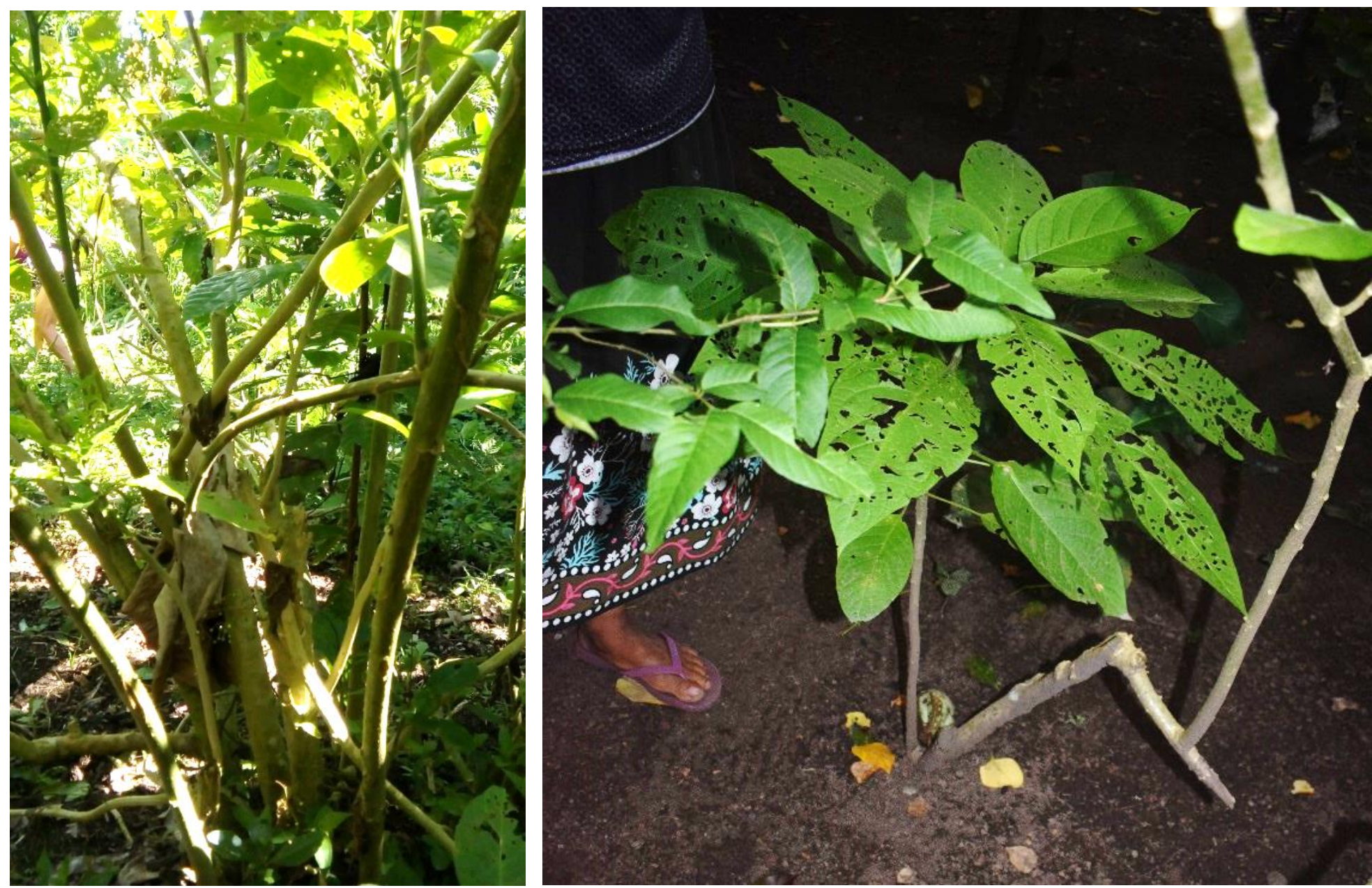

Figuras 1 y 2: Planta toé (San Martín, 2020 y Amazonas, 2018, respectivamente). 
La administración del toé se hacía en lugares alejados de la comunidad para evitar el ruido y las luces. Usualmente este momento era acompañado por las madres. Ellas daban sorbos de agua a sus hijos para mantener hidratados y recordaban cada palabra que ellos dijeron durante sus momentos de visión o "borrachería". La "borrachería" del toé llegaba a veces en forma de arañas y culebras, "eso refería que la planta estaba subiendo por el cuerpo". La gente del toé se presentaba también en forma de una boa grande, personas con coronas $\mathrm{y}$, en casos terapéuticos, en forma de doctores y doctoras - "cuando el toé es bueno, vienen esas enfermeras y doctores". La llegada de estos seres era el ingreso a un ámbito de visión alterna que era guiada por el espíritu del toé.

El "doctorcito del toé" era un hombre "que se veía como humano; flaco, esqueleto, de apariencia apách, siempre con bata, con ropa de doctor". La gente del toé llegaba en diferentes números y podía ser de distintos géneros. Estos seres eran: "flaquitas, mujeres y varones, que te atendían. Así como consulta [médica en el puesto de salud]. Ellos iban diciendo qué cosa estaba mal" (Señora Tania, Amazonas, 2018). Este "doctorcito", de apariencia no-indígena, vestido con ropa de médico, guiaba a las personas awajún en sus visiones, protegiéndolos de los peligros que también surgían en esta abertura a la alteridad. ${ }^{6}$

Durante la visión, el doctor del toé "te decía: '¿qué te duele?' Te decía que te va a ver. Te alzaba la ropa y te decía: "No tienes nada, solo dolores. No tienes enfermedad. Solo vas a tomar medicina. ¡Te vas a curar!”. Los consultorios de los “doctorcitos” era espacio lleno de luz donde diagnosticaban e incluso realizaban operaciones con instrumentos especializados y mucho personal médico. Algunos awajún decían que, durante estas atenciones, podían ver su piel traslucida y los órganos por detrás de la piel. Ellos veían la enfermedad o la brujería dentro de sus cuerpos en forma de "masas amarillas y negras", "huesos atravesados", "objetos o animales incrustados" con fuertes olores que emanaban del cuerpo. Los doctores del toé indicaban al paciente cómo debían sobarse o tratarse para curarse de ello. Por ejemplo, los doctorcitos indicaban cómo hacerse masajes a sí mismos y cómo chupar las partes del cuerpo donde se encuentran la enfermedad. Así, el toé y la persona extraían los elementos de enfermedad y traían bienestar al enfermo.

Cuando terminaba la consulta, el espíritu del toé comunicaba la mejoría: "Vas a estar mejor, vas a trabajar, vas a estudiar, vas a tener negocio”. ¡El toé te cura bonito!”. Luego de la visita a los doctores el espíritu de la planta también podía mostrar imágenes de la vida futura de la persona y de su familia. Se mostraba al enfermo la vida larga y bienestar de los demás miembros de su red. Así, luego de la visión de cura, la persona compartía con sus parientes estos caminos futuros mostrados por la planta, como, por ejemplo: que un hijo iba a estar sano, que el nieto iba a ir a la escuela, que el hermano iba a tener otro hijo, que la sobrina sería traviesa y que de grande iba a estudiar etc. Estas visiones a través de su

\footnotetext{
${ }^{6}$ Los especialistas tunchi o brujos tienen el deseo de dañar a las personas enfermas. El toé nublaba la visión del paciente y lo guiaba para no ser afectado por estos brujos y sus dardos invisibles. Los dardos tséntsak solo pueden ser sacados del cuerpo del enfermo con la intervención ritual de otro tunchi y con el poder de las plantas de poder.
} 
narración a los demás miembros de la familia daban certeza del futuro bienestar y vitalidad en la familia.

La cura del toé, sin embargo, solo se volvían realidad si después de la toma, el paciente respetaba las recomendaciones de dietas y tratamientos dadas por el espíritu del toé. Solo así la enfermedad extraída no volvía al cuerpo. Si el enfermo no cumplía con las dietas podía empeorar o incluso morir. Las primeras cuarenta y ocho horas luego de la toma del toé eran de gran peligro. Con la visión desenfocada y aún en borrachería, la madre del paciente volvía a intervenir aplicando ajíes ${ }^{7}$ (jíma) en las manos y pies del paciente. Ello era necesario para evitar ataques de los tunchis [brujos] y alejar los poderes excesivos que la planta podía haber transmitido inintencionalmente durante la visión. El poder del toé aún se estaba eliminando del cuerpo y por ello, la persona debía evitar salir de su casa, mantener una dieta estricta y evitar mirar directamente a los ojos de otras personas. Poco a poco, el poder del toé iba desapareciendo del cuerpo awajún.

Que alguien no cumpla los tratamientos dados por el toé causaba a su vez la pérdida del poder de la planta. La memoria y posible resentimiento del toé era algo especialmente mencionado por las personas awajún. Por ello, las mujeres preferían dar sus plantas de toé únicamente a personas de confianza en su red familiar. A quienes se sabía iban a ser responsables en cumplir los cuidados y resguardos necesarios. "Tenemos que cuidar nosotros mismos", comentaba la señora Tania: "Cuando a cualquiera le damos, el toé habla: 'jese no ha tenido dieta!' . ¡Y ya se malogra! no te cura para siempre”. Si, pese a los cuidados, la planta perdía su poder, las mujeres la sembraban nuevamente y la cuidaban siguiendo los resguardos descritos previamente. Así las mujeres renovaban su relación con el toé e iniciaban un nuevo ciclo de cuidados para que este vuelva a tener la capacidad de dar salud.

Como sugiere Shiratori (2019) en el caso del pueblo Jamamadi, las plantas tienen memorias y se asocian a los espacios familiares donde crecieron gracias a las acciones desplegadas por sus miembros. Sin embargo, esta relación entre las plantas y las personas es inestable. Ante cualquier acto irrespetuoso, las plantas pueden transformarse y abandonar el cuidado de las familias. Se tornan otros y su eficacia de cura disminuye; por ello, solo se comparten entre parientes.

\section{Palabras finales}

Nugkui, espíritu mítico femenino, dio a las mujeres awajún la capacidad de crear vida a través del profundo conocimiento de los seres del bosque, de las plantas y de los cultivos. Las mujeres, como nuevas hijas Nugkui, han sabido actualizar estos conocimientos y generan constantemente nuevas relaciones con seres humanos y no-humanos para dar vida y salud a sus hijos y parientes enfermos. En el caso del toé, estas páginas han mostrado cómo algunas mujeres awajún cuidan y curan a los miembros de su red a través de las relaciones que establecen con sus plantas.

Antiguamente, el toé era consumido por los y las awajún para encontrar la visión de vida larga y guerrera. Los abuelos y abuelas muun recordaban la manera como por medio del

\footnotetext{
${ }^{7}$ Descola (1998) también identificó el uso del ají luego de la toma de la planta en el pueblo achuar.
} 
toé era posible vencer a la vida corta y lograr tener una visión del futuro que acompañaba a las personas a lo largo de sus vidas. El toé les mostraba que iban a ser exitosos, que iban a tener una familia fuerte, unida e iban a vivir hasta ser ancianos sin sucumbir frente a las enfermedades ni la guerra. Si bien este proceso de formación de persona se ha transformado, el toé se ha mantenido como aliado de las familias gracias a su poder de diagnosticar y tratar diversas enfermedades y daños. En estas páginas hemos podido aproximarnos a las experiencias de algunas mujeres awajún, que establecieron relaciones de cuidado y de familiarización con sus plantas del toé. Estas relaciones solo fueron posibles gracias a la existencia de una cadena conocimientos, consejos y poderes que han sido transmitidas de abuelas a madres y de madres a hijas; en una red de relaciones que ha hecho posible el continuo hacer de las mujeres awajún como seres generadores de vida.

La centralidad de las madres en los procesos de salud se ha abordado en otros contextos etnográficos (Kopenawa y Albert, 2015; Belaunde, 2001; McCallum, 1998; Flores Rojas, 2019). Ellas, con apoyo de los demás miembros de la familia, proveen terapias y cuidados a sus hijos por medio de alimentación, uso de plantas y fármacos. Cuando una persona awajún cae enferma, la principal cuidadora es la madre. Ellas establecen un sistema de cuidado diario donde hacen seguimiento a los signos de debilidad, excreciones, sustancias, dolores, pensamientos, sueños y necesidades del pariente enfermo. Este seguimiento diario a sus diagnósticos y recaídas solo es posibles gracias a un entramado de relaciones con otros parientes y seres que dan forma constantemente a la persona awajún. Las madres mediante sus acciones haces cuerpos y hacen memorias. Ellas mantienen dinámicas las redes de relaciones que surgen en torno al hijo o hija enferma. El objetivo de las madres y de las familias es lograr la salud de sus miembros enfermos. Por ello, la cursa, en estos casos, se presenta en un campo de posibilidades amplio que involucra especialistas biomédicos, especialistas no-biomédicos y agentes de curación humanos y no humanos (Flores Rojas, 2019: 800).

La administración de la planta del toé en estos periodos es un intento más, junto a muchos otros, de lograr un diagnóstico y una cura. Lo central del toé es su capacidad de introducir al miembro enfermo a una visión alterna donde el cuerpo awajún se hace visibles en todas sus dimensiones a la gente, en especial, a los doctores del toé. El espíritu del toé guía y torna el cuerpo awajún, liberándolo de enfermedades, impurezas y dardos de daño incrustados. Contrario al continuo trabajo de las madres y las familias awajún por fijar la perspectiva de sus miembros para que no se tornen otros; con el cultivo, llamado y toma cuidadosa del toé, las mujeres dueñas de las plantas parecen promover en sus parientes enfermos un cambio de visión controlada. Donde luego de haber sido diagnosticados y tratados por los doctores de la planta, las madres y demás miembros de la red, toman nuevamente al miembro enfermo y cierran esa visión ampliada.

La capacidad de dar vida y salud a los miembros de la familia, hacen que el toé sea un ser apreciado por las mujeres y por la red de parientes awajún. El cuerpo awajún que me presentaron mis interlocutores no crecía naturalmente, era fabricado lenta y continuamente en un flujo constante de acciones que involucraban alimentos, abstención de ciertas actividades, aplicación de medicamentos, pinturas corporales, adornos, rituales y cuidados 
(Vilaça, 2005: 447). Los parientes y, en especial las madres y padres, cuidaban y tornaban fuerte el cuerpo de sus hijos e hijas. Sin embargo, la llegada de las enfermedades ponía en peligro este proceso. Por ello, las plantas de toé eran aliadas centrales para dar salud a sus miembros. Las hijas vegetales de la familia eran alimentadas, vestidas, llamadas y cuidadas por sus dueñas y dueños, a cambio las plantas daban salud a sus parientes. La familia awajún que me mostraron mis interlocutores parece ser una red de relaciones más que humana. Donde plantas, seres y personas crecen y se hacen continuamente por medio de relaciones de cuidado y de afinidad. Las personas awajún cuidan de sus plantas de toé y las plantas, a su vez, cuidan de ellas y de sus parientes. Pensar la salud indígena inserta en este mundo relacional, de complementariedad y de cuidado mutuo entre las personas y sus plantas, puede impulsar otras discusiones sobre los modos particulares de dar salud y de dar vida en los contextos indígenas. Ello sin excluir las demandas del pueblo awajún por mejores sistemas biomédicos de atención.

\section{Bibliografía}

BELAUNDE, Luisa. 2019. "O ninho do Japu: perspectivismo, gênero e relações interespécies airo-pai”. Amazônica, vol. 11, n. 2: 657-689. DOI 10.18542/amazonica.v11i2.7638

BELAUNDE, Luisa. 2001. Viviendo Bien. Género y fertilidad entre los airo pai de la Amazonía Peruana. Lima: CAAAP.

BROWN, Michael. 1984. Una paz incierta. Historia y cultura de las comunidades aguarunas frente al impacto de la carretera marginal. Lima: CAAP.

BROWN, Michael. 1978. "From the hero ś bones: three aguaruna hallucinogens and their uses”. FORD, Richard. (Ed.). The nature and status of ethnobotany. Michigan: University of Michigan, pp. 178-136. (Anthropological Papers $\mathrm{N}^{\circ}$. 67).

CHUMAP, Aurelio; Manuel GARCÍA. 1979. Duik múun: universo mítico de los aguaruna. Lima: CAAAP

DESCOLA, Philippe. 2005. Las lanzas del crepúsculo. Relatos jíbaros. Alta Amazonía. Argentina: Fondo de Cultura Económica.

DESCOLA, Philippe. 2008. "Estrutura ou Sentimento: a relação com o animal na Amazônia". Mana - Estudos de Antropologia Social, vol. 4, n. 1: 23-45. DOI: 10.1590/S010493131998000100002

ERIKSON, Philippe. 2012. "Animais demais... os xerimbabos no espaço doméstico matis (Amazonas)”. Anuário Antropológico, vol. 37, n. 2: 15-32. DOI 10.4000/aa.110

FAUSTO, Carlos. 2008. “Donos Demais: Maestria e Domínio na Amazônia”. Mana - Estudos de Antropologia Social, v. 14, n. 2: 329-366. DOI https://doi.org/10.1590/S010493132008000200003

FLORES ROJAS, Ximena. 2020. “VIH/sida awajún': nociones y experiencias de enfermedad y daño en un contexto de epidemia en la Amazonía peruana”. Anthropologica, vol. 38, n. 44: 235-266. DOI 10.18800/anthropologica.202001.010 
FLORES ROJAS, Ximena. 2019. "Entre játa y waweamu: VIH/sida en las comunidades awajún de la Amazonía peruana”. Mana - Estudos de Antropologia Social, vol. 25, n. 3: 777808. DOI 10.1590/1678-49442019v25n3p777

GIUCAM, Cesar; Elvin, RAMOS. 2015. "Cuentos tradicionales awajún de los estudiantes en la Institución Educativa Bilingüe Nº16741 Kusu Kubaim”. Pucallpa, Tesis de Licenciatura, Universidad Nacional Intercultural de la Amazonía.

GUALLART, José María. 1990. Entre Pongo y Cordillera. Lima: CAAAP.

KOPENAWA, David; LBERT, Bruce. 2015. A queda do céu: palavras de um xamã yanomami. São Paulo: Companhia das letras.

LANGDON, Esther Jean. 2014. La negociación de lo oculto: Chamanismo, medicina y familia entre los Siona del bajo Putumayo. Popayan: Universidad del Cauca.

LIMA, Tânia Stolze. 2005. Um peixe olhou para mim. O povo Yudjá e a perspectiva. Río de Janeiro: Unesp Editora.

MAIZZA, Fabiana. 2017. "Persuasive Kinship: Human-Plant Relations in Southwest Amazonia." Tipiti vol. 15, n. 2: 206-220

MENTORE, Laura. 2012. "The Intersubjective Life of Cassava among the Waiwai." Anthropology and Humanism 37 (2):146-155

MCCALLUM, Cecilia. 1998. "O corpo que sabe da epistemologia Kaxinawa para uma antropologia médica das terras baixas sul-americanas”. In: RABELO, Miriam Cristina; ALVES, Paulo Cesar. (Orgs). Antropologia da saúde: traçando identidade e explorando fronteiras. Rio de Janeiro: FIOCRUZ. pp. 215-245.

MORIM DE LIMA, Ana Gabriela. 2016. "Brotou batata para mim”: cultivo, género e ritual entre os Krahô. Rio de Janeiro, Tese de doutorado, Universidade Federal do Rio de Janeiro.

NUGKUI; BOSQUE DE LAS NUWAS. 2021. Nugkui untsumau: El llamado de Nugkui. Moyobamba: CAAAP \& MINCUL.

REGAN, James. 2010. "Los awajún y wampis contra el Estado: una reflexión sobre antropología política”. Investigaciones sociales, vol. 14, n. 24: 19-35.

RIVAL, Laura. 2004. "El crecimiento de las familias y de los árboles: la percepción del bosque de los Huaorani”. In: SURRALLÉS, Alexandre; GARCIA HIERRO, Pedro (Eds.). The land within: indigenous territory and perception of the environment. Copenhagen: IWGIA (International Work Group for Indigenous Affair).

SHEPARD, Glenn. 2019. "Toé (Brugmansia suaveolens): o caminho do dia e o caminho da noite”. Em: GOULARD, Sandra; LABATE, Beatriz. (Eds.). O uso de plantas psicoativas nas américas. São Paulo: Gramma, pp. 118-134.

SHIRATORI, Karen. 2019. "O olhar envenenado: a perspectiva das plantas e o xamanismo vegetal jamamadi”. Mana - Estudos de Antropologia Social, v. 25, n. 1: 159-188. DOI https://doi.org/10.1590/1678-49442019v25n1p159

TAJUPUT, Edison. 2010. Comentario de la Colección Cuentos Pintados del Perú (Asháninka, Shipibo-Konibo y Awajún. Lima: Periódicos PUCP.

TAYLOR, Anne-Christine. 2000. «Le sexe de la proie. Représentation jivaro du lien de parenté ». L’Homme: vol. 154-155: 309-334. DOI 10.4000/lhomme.35 
VILAÇA, Aparecida. 2005. "Chronically unstable bodies. Reflexions on Amazonian corporalities". The Journal of the Royal Anthropological Institute, vol.11, n. 3: 445-464. DOI 10.1111/j.1467-9655.2005.00245.x

VIVEIROS DE CASTRO, Eduardo. 2013. La mirada del jaguar. Introducción al perspectivismo amerindio. Entrevistas. Buenos Aires: Tinta Limón.

\section{"El toé te cura bonito": modos femininos de dar saúde entre os Awajún (Amazônia Peruana)}

resumo Este artigo apresenta as primeiras reflexões sobre o uso da fitoterapia nas famílias Awajún das regiões de San Martín e Amazonas. Em particular, abordo as relações que as mulheres Awajún apresentam com suas usinas como o toé (Brugmansia suaveolens) que é plantada, cuidada, chamada e preparada por algumas mães Awajún com o objetivo de dar vida e saúde a seus filhos e filhas doentes. A relação que cada mulher estabelece com as plantas dos pés é única. Semelhante aos processos de formação de pessoas, as mulheres donas das plantas voltam e reconhecem a existência de seus filhos vegetais cuidando deles, trocando substâncias, dietas e salvaguardas. Em reciprocidade, essas crianças vegetais se materializam como especialistas terapêuticos capazes de dar saúde e vida às famílias Awajún.

palavras-chaves Mulheres, awajún, plantas, toé, cuidado, adoecimento.

\section{sobre la autora}

\section{Ximena Maria Flores Rojas}

Estudiante de doctorado en el Programa de Posgrado en Antropología Social del Museo Nacional de la Universidad Federal de Río de Janeiro.

Autoría: Ximena Flores Rojas fue responsable por la recogida de los datos, su sistematización y el análisis que hacen parte de este articulo

Financiación: La escritura del articulo fue posible por las becas de CAPES-Brasil y PPGAS/Museu NacionalWenner-Gren Foundation.

Fecha de recibimiento: 18/07/2021

Fecha de aprobación: 12/12/2021 